\title{
SEXUAL DEVELOPMENT AND BEHAVIOUR ISSUES IN POLISH TEENAGE MAGAZINES
}

\author{
Marek S. Kopacz
}

Jagiellonian University College of Medicine, Department of Medical Sociology, Kraków, Poland

\section{SUMMARY}

Introduction: Adolescents often look to mass media for information regarding issues of sexuality. As one form of media, teenage magazines have long constituted a pervasive and effective element of adolescent media exposure. Teenage magazines discuss a number of aspects concerning adolescent sexuality. Considering their potential impact on health related behaviors, the information they provide and the message(s) they send warrant attention.

Aim/Purpose: The aim of this study is to perform a content analysis of sexual development and behavior information presented in Polish teenage magazines. Social Cognitive Theory was used as a theoretical basis for this analysis.

Methods and Materials: The media chosen for this study were general-themed publications targeting an adolescent female audience: Bravo Girl!, Filipinka and Dziewczyna. Each entry was analyzed using a structured key. The specific categories of behavior and development used for this study are: biological information, pedagogic instruction, topics of moral-ethical concern, results of sexual activity, and interpersonal relationships. Each category was then subdivided into separate units.

Results: The findings indicate that Polish teenage magazines predominantly focus on relationships, contraception and sex education. Relationships were most often of a romantic nature and discussed sexual activity or the potential of sexual activity. Non-prescription contraceptive methods were most often discussed, with attention given to pregnancy prevention. Sex education offered detailed information on sexual practices and behaviors with much discussion on losing one's virginity.

Conclusions: The general approach of the analyzed magazines is that adolescents currently are, or soon will be, sexually active. As a result, certain sexual behavior and development issues are discussed in great detail, while other topics are somewhat neglected. Accepting informationseeking during adolescence as commonplace, these findings suggest that teenage magazines hold the potential for influencing adolescent sexual behavior and development.

Key words: sex education, mass media, teenage pregnancy

Address for correspondence: M. S. Kopacz, Jagiellonian University, College of Medicine, Department of Medical Sociology, Chair of Epidemiology and Preventive Medicine, ul. Kopernika 7a, 31-034 Kraków, Poland. E-mail: marekskopacz@hotmail.com

\section{INTRODUCTION}

Current literature offers much insight on adolescent sexual behaviors and the possible influences on such behavior. Youth often look for their social contexts and clues about what constitutes acceptable sexual behavior (1). Mass media is one such community sphere that influences and shapes children's health (2). Some adolescents look for information about a range of health topics and often resource lay impersonal sources of information, including mass media (3). This has linked certain media to a decreased reliance on health professionals (3). Information-seeking relates to life tasks that take on special importance during adolescence because of the extensive biological, psychological, and social changes occurring in adolescence (4). For girls in particular, this marks a transition period from child to teen when they start negotiating a set of structures and meanings that more fully inscribe their subordination on the basis of gender (5).

As one form of media, magazines marketed to adolescent girls can be seen to play a particularly active role in adolescent sexual development and behavior. Teen magazines are a power- ful influence, defining what is meaningful to teenage girls and helping to shape their attitudes and behavior (6). They may serve to provide a context for girls to interpret themselves (7). Most studies show that teenagers learn "the facts of life" from chit-chat amongst their peers and from magazines (8). Some young adults seize upon magazines to acquire knowledge about sexuality (9). Young girls read magazines to learn about sex and three-fourths of white females aged 12-14 read at least one magazine monthly $(4,10)$. Also, adolescents see magazines as useful sources of information about sexual health and a vital means of learning about topics that are difficult to broach with friends or parents (11). For example, when students were asked where they received most of their knowledge about contraceptives, magazines were listed among the most common responses (12). For teenage girls, it could be argued that magazines are one of the most accessible, inexpensive, and readily available media for information about sexuality (13).

Teen girls' and women's magazines have increased their coverage of sexual health issues over the past decade (14). In Poland, rivalry between adolescent magazine publishers has 
increased as the demand for magazines of an educational-character is great (15). Also, advances in education and the popularization of sexual issues in women's magazines have added support to Polish women in their aspirations towards implementing their sexual rights and providing for their own needs (16). Mandatory education in Poland includes sex education classes mirroring the abstinence-only model. With respect to mass media, one promising element of abstinence-based programs has been addressing social and media influences upon adolescent sexual behavior and how these influences differ from family values and health practices (17). However, in the context of greater Polish society, adolescent sexuality is still considered a taboo topic. Polish studies find that popular culture and mass media, particularly television and print media, have assumed the role of educator and, to a large degree, shape the knowledge, attitudes and behaviors of adolescents with regards to sexuality (18).

The need to evaluate the content of teenage magazines is illustrated by their function as an information source and their effect on adolescent sexual development and behavior. The aim of this study is to perform a content analysis of sexual development and behavior information presented in Polish teenage magazines. This study refers only to magazines meeting the following criteria: nationally available, general-themed, and marketed to adolescent girls. To the best knowledge of the author, this study expands on available literature since no previous study has analyzed the content of Polish teenage magazines in this respect.

Social Cognitive Theory is used as a theoretical basis for this study. Media stimulates, reinforces, and reproduces an objectifying gaze through its portrayal of interpersonal social interactions (7). Through a continuative process of communication, individuals learn definitions of certain behaviors as either appropriate or inappropriate (19). Adolescents will observe and imitate the specific behaviors learned, the behavior will then be socially reinforced, and the adolescent will expect positive consequences from their future involvement in the behavior (20). Through their portrayal of sex as glamorous, pleasurable, and adult, teenage magazines develop elaborate sets of ideas concerning sexuality and sexual roles well before adolescents actually engage in sexual activity $(21,22)$. It follows that adolescents who attend to media content that includes depictions of attractive characters who rarely suffer any negative consequences of sexual intercourse will be likely to imitate the behavior (14).

\section{MATERIALS AND METHODS}

Three magazines fitting the criteria were chosen for this study: Bravo Girl!, Dziewczyna and Filipinka. These titles in particular were chosen as they best represent a variety of the kinds of magazines Polish adolescent girls read. 34.9\% of adolescent girls read Bravo Girl!, 43.0\% read Dziewczyna, and 8.7\% read Filipinka (18). Of the fifty-three titles classified in Poland as "Publications for Children and Adolescents," Bravo Girl!, Dziewczyna and Filipinka respectively ranked 3rd, 5 th and 11 th in terms of circulation (23). The following is an official description of each title, taken from the internet pages of each respective publisher.

Bravo Girl! is an advice-oriented magazine marketed to 15-19-year-old girls living in small and medium sized cites. Each issue discusses topics dealing with fashion, health, celebrities, education, affairs of the heart and "fun topics" (24). Dziewczyna is targeted towards 15-18-year-old teenage girls interested in fashion, a healthy lifestyle and topics connected with the transition to adulthood. This magazine also profiles famous people and other celebrities (25). Middle- to upper-class, success-oriented high school students make up the 15-22-year-old target audience of Filipinka. This magazine focuses on fun topics, cultural and social issues, the latest fashion and cosmetic trends and advice on school, career, money, health, psychology and intimate issues (26).

The study analyzed four years of publications for each respective title. For Bravo Girl!, a bi-monthly publication, 104 issues from 2001-2005 were included in the analysis. For Dziewczyna, a monthly publication, forty-eight issues from 2000-2002 and 2004 were included in the analysis. For Filipinka, a monthly publication, forty-eight issues from March 2001-February 2005 were included in the analysis. The entire content of a magazine was subject to analysis. For the purpose of this study, an entry was defined as any non-fictional piece of writing (e.g. article, letter, etc.) which dealt with adolescent sexual behavior and/or development issues. Each entry was then coded using a structured key designed by the author under the auspices of senior faculty members. In total there were 1,683 entries qualified into the study. All entries were coded by the author, a physician with training in medical sociology.

The categories of sexual behavior and development used for this study are: biological information, pedagogic instruction, interpersonal relationships, topics of moral-ethical concern, and the eventual results of sexual activity. These categories were chosen because they best represent the dimensions of competence regarding sexuality: factual knowledge about the physical processes of one's own body and the body of a partner, fertility and contraception and the existence of and protection against sexually transmitted diseases (27). "Topics of moral-ethical concern" were included because some authors have argued that the main concern surrounding issues of adolescent sexuality is related to matters of physical health and not focused on moral or ethical issues (28). Each category was then subdivided into separate recording units. Table 1 offers a detailed description of the categories and recording units used for this study. Often an entry would discuss more than one topic simultaneously. When a clear distinction could be made, it was possible for an entry to be coded into multiple categories and recording units.

\section{RESULTS OF CONTENT ANALYSIS}

Table 2 presents the results of content analysis.

Interpersonal relationships was the most often coded category. This category constituted over half of all analyzed entries. Especially prevalent in this category were quizzes which gauged the potential for relationship success, the results of which placed the girl and/or her (potential) partner into a specific grouping. Romantic relationships accounted for more than $50 \%$ of this category. Topics most often discussed were sexuality, deeper emotional connections/bonding, general disagreements, infidelity, issues of partner compatibility, and disagreeable behavior on the part of the partner. Entries concerning relationships between peers included situations where two individuals develop feelings for the same partner ("love triangles"), thwarting unwanted advances, 
Table 1. Detailed descriptions

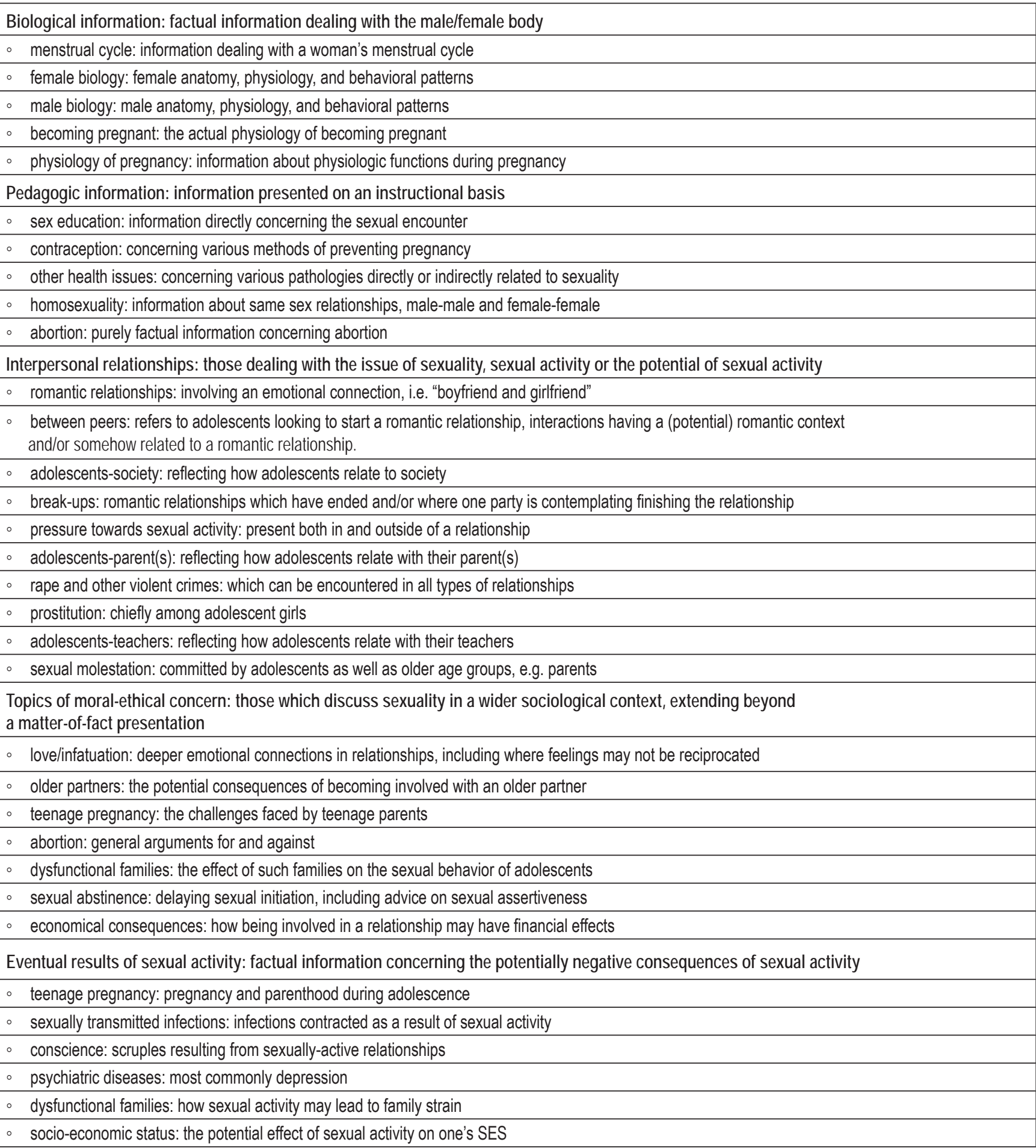

effective flirting, picking an ideal boyfriend and dealing with the boyfriend's peer group. The general theme of this category was on advising the girl how to accommodate herself to a variety of situations.

Pedagogic instruction follows interpersonal relationships as the second most popular category. This category constituted a quarter of all entries. The topics most often talked about were sex education, contraception, and health issues. Sex education dealt with instruction about specific sexual practices, fetishes, pain during deflowering, and sexual ethics. This included very detailed instruction on oral sex, anal sex, comfortable sexual positions for losing one's virginity and different types of sexual behavior. Discussion of natural family planning as well as other contraceptive methods (e.g. condoms, diaphragms) would often recur. A condom-vaginal sponge combination was presented as the ideal form of contraception for girls engaging in spontaneous sexual contacts. The contraceptive pill was presented as ideal for girls with regular sexual contacts. Overall, there was considerable mention of the contraceptive pill as a contraceptive method. Reasons for prescribing "the pill" not associated with contraception 
Table 2. Content analysis

\begin{tabular}{|c|c|c|c|c|c|c|c|c|}
\hline \multirow[b]{2}{*}{ General area of knowledge } & \multicolumn{2}{|c|}{ Filipinka } & \multicolumn{2}{|c|}{ Bravo Girl! } & \multicolumn{2}{|c|}{ Dziewczyna } & \multicolumn{2}{|c|}{ Summary } \\
\hline & N & $\%$ & N & $\%$ & $\mathrm{~N}$ & $\%$ & N & $\%$ \\
\hline - interpersonal relationships & 238 & $46.4 \%$ & 494 & $51.9 \%$ & 249 & $53.8 \%$ & 981 & $50.9 \%$ \\
\hline - pedagogic information & 136 & $26.5 \%$ & 257 & $27.0 \%$ & 109 & $23.5 \%$ & 502 & $26.1 \%$ \\
\hline - biological information & 70 & $13.6 \%$ & 146 & $15.4 \%$ & 59 & $12.7 \%$ & 275 & $14.3 \%$ \\
\hline - topics of moral-ethics concern & 45 & $8.8 \%$ & 34 & $3.6 \%$ & 39 & $8.4 \%$ & 118 & $6.1 \%$ \\
\hline - eventual results of sexual activity & 24 & $4.7 \%$ & 20 & $2.1 \%$ & 7 & $1.5 \%$ & 51 & $2.6 \%$ \\
\hline \multicolumn{9}{|l|}{ Interpersonal relationships } \\
\hline - romantic relationships & 152 & $56.5 \%$ & 290 & $55.8 \%$ & 136 & $51.3 \%$ & 578 & $55.1 \%$ \\
\hline - between peers & 41 & $15.2 \%$ & 105 & $20.2 \%$ & 45 & $17.0 \%$ & 191 & $18.2 \%$ \\
\hline - adolescents-society & 22 & $8.2 \%$ & 20 & $3.8 \%$ & 7 & $2.6 \%$ & 49 & $4.7 \%$ \\
\hline - break-ups & 21 & $7.8 \%$ & 47 & $9.0 \%$ & 16 & $6.0 \%$ & 84 & $8.0 \%$ \\
\hline - pressure towards sexual activity & 15 & $5.6 \%$ & 22 & $4.2 \%$ & 20 & $7.5 \%$ & 57 & $5.4 \%$ \\
\hline - adolescents-parents & 13 & $4.8 \%$ & 20 & $3.8 \%$ & 24 & $9.1 \%$ & 57 & $5.4 \%$ \\
\hline - rape and other violent crimes & 3 & $1.1 \%$ & 9 & $1.7 \%$ & 7 & $2.6 \%$ & 19 & $1.8 \%$ \\
\hline - prostitution & 2 & $0.7 \%$ & 1 & $0.2 \%$ & 5 & $1.9 \%$ & 8 & $0.8 \%$ \\
\hline adolescents-teachers & 0 & $0.0 \%$ & 3 & $0.6 \%$ & 3 & $1.1 \%$ & 6 & $0.6 \%$ \\
\hline - sexual molestation & 0 & $0.0 \%$ & 3 & $0.6 \%$ & 2 & $0.8 \%$ & 5 & $0.5 \%$ \\
\hline - mean percentage * & \multicolumn{2}{|c|}{$46.7 \%$} & \multicolumn{2}{|c|}{$51.5 \%$} & \multicolumn{2}{|c|}{$54.5 \%$} & \multicolumn{2}{|c|}{$50.9 \%$} \\
\hline \multicolumn{9}{|l|}{ Pedagogic information } \\
\hline - sex education & 58 & $40.3 \%$ & 99 & $36.4 \%$ & 35 & $30.7 \%$ & 192 & $36.2 \%$ \\
\hline - contraception & 31 & $21.5 \%$ & 87 & $32.0 \%$ & 34 & $29.8 \%$ & 152 & $28.7 \%$ \\
\hline - other health issues & 38 & $26.4 \%$ & 73 & $26.8 \%$ & 39 & $34.2 \%$ & 150 & $28.3 \%$ \\
\hline - homosexuality & 16 & $11.1 \%$ & 13 & $4.8 \%$ & 4 & $3.5 \%$ & 33 & $6.2 \%$ \\
\hline - abortion & 1 & $0.7 \%$ & 0 & $0.0 \%$ & 2 & $1.8 \%$ & 3 & $0.6 \%$ \\
\hline - mean percentage * & \multicolumn{2}{|c|}{$25.0 \%$} & \multicolumn{2}{|c|}{$27.0 \%$} & \multicolumn{2}{|c|}{$23.5 \%$} & \multicolumn{2}{|c|}{$25.6 \%$} \\
\hline \multicolumn{9}{|l|}{ Biological information } \\
\hline - menstrual cycle & 12 & $15.2 \%$ & 68 & $42.5 \%$ & 31 & $51.7 \%$ & 111 & $37.1 \%$ \\
\hline - female biology & 52 & $65.8 \%$ & 41 & $25.6 \%$ & 17 & $28.3 \%$ & 110 & $36.8 \%$ \\
\hline - male biology & 15 & $19.0 \%$ & 40 & $25.0 \%$ & 6 & $10.0 \%$ & 61 & $20.4 \%$ \\
\hline - becoming pregnant & 0 & $0.0 \%$ & 9 & $5.6 \%$ & 6 & $10.0 \%$ & 15 & $5.0 \%$ \\
\hline - physiology of pregnancy & 0 & $0.0 \%$ & 2 & $1.3 \%$ & 0 & $0.0 \%$ & 2 & $0.7 \%$ \\
\hline - mean percentage * & \multicolumn{2}{|c|}{$13.7 \%$} & \multicolumn{2}{|c|}{$15.9 \%$} & \multicolumn{2}{|c|}{$12.3 \%$} & \multicolumn{2}{|c|}{$14.4 \%$} \\
\hline Topics of moral-ethical concern & & & & & & & & \\
\hline - love/infatuation & 26 & $54.2 \%$ & 20 & $55.6 \%$ & 31 & $81.6 \%$ & 77 & $63.1 \%$ \\
\hline - older partners & 12 & $25.0 \%$ & 12 & $33.3 \%$ & 3 & $7.9 \%$ & 27 & $22.1 \%$ \\
\hline - teenage pregnancy & 3 & $6.3 \%$ & 1 & $2.8 \%$ & 3 & $7.9 \%$ & 7 & $5.7 \%$ \\
\hline - abortion & 3 & $6.3 \%$ & 1 & $2.8 \%$ & 1 & $2.6 \%$ & 5 & $4.1 \%$ \\
\hline - dysfunctional families & 3 & $6.3 \%$ & 0 & $0.0 \%$ & 0 & $0.0 \%$ & 3 & $2.5 \%$ \\
\hline - sexual abstinence & 0 & $0.0 \%$ & 2 & $5.6 \%$ & 0 & $0.0 \%$ & 2 & $1.6 \%$ \\
\hline - economical consequences & 1 & $2.1 \%$ & 0 & $0.0 \%$ & 0 & $0.0 \%$ & 1 & $0.8 \%$ \\
\hline - mean percentage * & $8.3 \%$ & & $3.6 \%$ & & $7.8 \%$ & & $5.9 \%$ & \\
\hline Eventual results of sexual activity & & & & & & & & \\
\hline - teenage pregnancy & 14 & $38.9 \%$ & 9 & $42.9 \%$ & 3 & $33.3 \%$ & 26 & $39.4 \%$ \\
\hline - sexually transmitted infections & 12 & $33.3 \%$ & 10 & $47.6 \%$ & 5 & $55.6 \%$ & 27 & $40.9 \%$ \\
\hline - conscience & 5 & $13.9 \%$ & 1 & $4.8 \%$ & 0 & $0.0 \%$ & 6 & $9.1 \%$ \\
\hline - psychiatric diseases & 2 & $5.6 \%$ & 0 & $0.0 \%$ & 1 & $11.1 \%$ & 3 & $4.5 \%$ \\
\hline - dysfunctional families & 2 & $5.6 \%$ & 0 & $0.0 \%$ & 0 & $0.0 \%$ & 2 & $3.0 \%$ \\
\hline - socio-economic status & 1 & $2.8 \%$ & 1 & $4.8 \%$ & 0 & $0.0 \%$ & 2 & $3.0 \%$ \\
\hline - mean percentage * & $6.3 \%$ & & $2.1 \%$ & & $1.9 \%$ & & $3.2 \%$ & \\
\hline
\end{tabular}

* percentages are presented as a mean for the entries in each respective magazine 
were also discussed. The health issues most often talked about included yeast infections, urinary tract infections, irregular menstrual cycles, and dyspareunia as a common complaint of sexually active girls. Where applicable, non-prescription treatment options were first presented followed by the need to visit a physician for prescription methods. Visiting a gynecologist, if only for prophylactic reasons, was suggested to all readers.

Biological information accounted for $14 \%$ of all entries. For Bravo Girl! and Dziewczyna, most attention was paid to the menstrual cycle and first menstruation. Emphasis was always placed on first menstruation as defining the transition from girl to woman and the consequent risk of becoming pregnant. Biological information accounted for $14 \%$ of Filipinka. This magazine, however, devoted most of its attention to female biology, where emphasis was placed on the development of secondary sexual characteristics. This category would also discuss the risk of becoming pregnant through non-coital behaviors (e.g. petting, etc.) and rupture of the hymen through non-coital behaviors, with the consequent effect on "virginity status".

Topics of moral-ethical concern and the eventual results of sexual activity each comprised less than $10 \%$ of entries. Love/infatuation accounted for more than $50 \%$ of moral-ethical recording units in each magazine. Most often this took the form of questions if love is present in a relationship, summer holiday romances and the potential for couples to survive summer holidays apart. The most often discussed eventual results of sexual activity were teenage pregnancy and sexually transmitted infections (STIs). Teenage pregnancy was presented in a matter-of-fact manner, disqualifying such an entry exclusively as a topic of moral-ethical concern. Teenage pregnancy and adolescent motherhood were presented as a difficult transition period with an ultimate positive outcome. Contact information for national crisis centers was most often included with such entries.

An overwhelming majority of all entries were letters from readers. Readers would submit letters, most often asking questions, and they would be answered in separate sections titled "experts answer your questions", commonly referred to as advice columns. Advice columns would be headlined by one or more named experts. The experts which would answer these letters almost always included psychologists, physicians (especially gynecologists) and/or sexologists.

With some mention of recommending a given product, a number of entries were actually covert advertisements. Such an approach was most often seen in entries coded for biological information and pedagogic instruction. The products most often "recommended" were feminine hygiene and contraceptive products. This included brand-name condoms, vaginal sponges and contraceptive pills. The small percentage of direct advertising was always separated from published text by a thin black line, with "advertisement" printed in small letters. Certain advertising took the form of advice columns sponsored by a company and answered by an expert. There were also advertisements using letters to highlight the value of having contraception "just in case". On a few occasions there was mixed text, for example, an article matched with an advertisement of a book on female health.

Reliability was assessed using Cohen's Kappa coefficient to test for stability (29). This was done whereby, following the complete initial analysis of all three magazines, $10 \%$ of issues for each respective magazine were randomly selected and coded
Table 3. Reliability Values

\begin{tabular}{|l|l|l|l|}
\cline { 2 - 4 } \multicolumn{1}{c|}{} & Filipinka & Bravo Girl! & Dziewczyna \\
\hline General area of knowledge & $K=0.82$ & $K=0.86$ & $K=0.82$ \\
\hline Interpersonal relationships & $K=0.79$ & $K=0.82$ & $K=0.74$ \\
\hline Pedagogic information & $K=0.85$ & $K=0.71$ & $K=0.76$ \\
\hline Biological information & $K=0.69$ & $K=0.84$ & $K=0.81$ \\
\hline Topics of moral-ethical concern & $K=0.74$ & $K=0.63$ & $K=0.73$ \\
\hline Eventual results of sexual activity & $K=0.79$ & $K=0.79$ & $K=0.69$ \\
\hline
\end{tabular}

once again. Results of reliability testing are presented in Table 3. A kappa coefficient of 0.61 is considered indicative of reasonably good overall agreement (30).

\section{DISCUSSION}

The aim of this study was to perform a content analysis of sexual development and behavior information presented in Polish teenage magazines. The results find that the focus of teenage magazines is on romantic relationships, potentially romantic relationships, sex education and contraception. This focus did not change over time and there were only minimal differences between magazines. The manner in which these topics were presented is similar to previous studies finding print media assume that readers are, or soon will be, engaging in sexual activity (13).

Relationships provide a context for the formation of beliefs about the self and the world and the growth of interpersonal competencies (31). During adolescence especially, dating and sexual activity may serve as a marker of status achievement upon which adolescents place considerable importance (32). In line with Social Cognitive Theory, these magazines provide a canvas for observing the kinds of behaviors some adolescents may be imitating within their own relationships. One of the factors by which Social Cognitive Theory explains human interpersonal behavior is risk perception (33). Positive reinforcement for behavior imitation could then be found in competency gained through newfound relationship skills, sex education and contraceptive knowledge, whereby sex becomes more pleasurable and void of negative consequences, such as unplanned adolescent pregnancy.

Of particular interest is that letters from readers constituted a majority of entries. Similar to other studies, one may presume that these teenage magazines responded to the demands of readers by inviting them to ask questions regarding relationships and publishing letters to the editor asking explicit questions about sexuality (27). One must place this observation in the context of greater Polish society where adolescent sexuality is often considered a taboo topic. At times, girls hear the suggestion that breaking with the awkward standards imposed upon them by parents and religion leads to menacing internal conflicts, which give rise to doubts about how far one can proceed in the sphere of sexual behaviors (34). Teens often feel so guilty about violating social taboos that they are often emotionally incapable of using their knowledge to make the conscious decisions about sexual behavior needed to prevent untoward consequences (35). Perhaps publishers of teenage magazines are reluctant to print regular articles and would rather satisfy the demand for sexual 
development and behavior information among Polish adolescents by printing reader-initiated material.

The pervasive mention of menstruation and older partners warrants discussion. Studies find that adolescent sources of information about menstruation include girls' magazines (36). Menstruation, as a marker of puberty, is a measure of female biological maturity. However, part of the controversy surrounding teenage sexuality is that there is no clear marker for when cognitive maturity is reached. The results of several studies suggest that the timing of puberty influences the onset and extent of heterosexual behavior (37). Earlier menarche is associated with earlier age at dating men and older age of first sexual intercourse partner relative to own age at first intercourse (i.e. difference between own and partner's age) (38). Girls with older boyfriends are usually more likely than girls with similar-aged boyfriends to engage in intimate touching, as well as oral, anal, and vaginal sex (31). Such sexual behaviors involve exchange of fluid and are thus salient for STD acquisition (39).

Sexual behaviors that cause STDs and unintended pregnancies represent a category of behavior resulting in many major health problems (40). The volume of contraceptive information these magazines provide makes them a potential source of knowledge for adolescents seeking information on contraceptive pills and other non-prescription contraceptive methods. This result mirrors studies finding condoms and contraceptive pills as the most popular contraceptives for the under 20s (41). However, this information was chiefly presented with pregnancy prevention in mind. Of note is the relatively minimal attention paid to STI prevention. This fact is troubling considering females aged 15-19 years have, for example, the highest rate of STDs compared to other age and gender groups (42).

Mature sexual development rests not only in knowledge, but in how to resist pressures to become involved in unwanted or early sexual intercourse (43). Studies find peer relationships, issues of abstinence or celibacy, and contraception remain important dimensions for adolescents (44). Though issues of abstinence or celibacy were touched upon in these magazines, by no means were they extensively developed. The analyzed publications did not effectively promote any sexual standards beyond sexual activity or the prospect of sexual activity. This leads one to question in what manner - positively or negatively - do Polish teenage magazines contribute to the sexual development of Polish adolescents? Nonetheless, correlational studies indicate that whether sexually active teens seek out sexual content or whether sexual content increases sexual activity remains uncertain (10). However, one may still observe the potential for better developing teenage magazines to include these topics.

One shortcoming of traditional mass media is that it is characterized by the one-way flow of information from the producer to the recipient (3). For this reason, parents and schools must place emphasis on adapting to what teenagers need in terms of support, education, and guidance (45). The health of adolescents is not the sole responsibility of health care facilities or adolescents themselves, but rather is shaped by multiple contexts, and the changes that take place within these contexts (46). Ideally, one may assume sexual coming-of-age should not be predicated solely on the influence of mass media (e.g. magazines). Community-based sexual health programs designed to assist young people in developing social norms supportive of delaying sex and raising their awareness of how early sexual initiation may threaten future plans, may reduce the prevalence of adolescent risky sexual behavior (47). Adolescent sex education is probably the most cost-effective intervention that could be made to ensure the future reproductive health of the community (8).

\section{LIMITATIONS}

This study was limited only to the analysis of sexual development and behavior issues. For this reason, the author makes no claims concerning the frequency of occurence of these issues in relation to other topics. Bias may have resulted from reliability testing for stability rather than reproducibility. Due to library limitations, it was at times not possible to choose the same years of publication for all magazines and there may also have been issues missing from the library catalogue. For Bravo Girl!, issues from 2001-2004 were analyzed, with the exception of three issues from 2001 and one issue from 2002 which were missing. In an effort to reduce bias, four issues from 2005 were as a result added into the analysis. For Dziewczyna, 2003 was missing from the library catalogue; otherwise all issues for the years 2000-2002 and 2004 were available for analysis. For Filipinka, all issues for the period March 2001-February 2005 period were available for analysis. As a recommendation for future research, a similar content analysis may be performed where reliability is measured by reproducibility and all magazines correspond to the same years of publication.

\section{REFERENCES}

1. Shoveller JA, Johnson JL, Langille DB, Mitchell T. Socio-cultural influences on young people's sexual development. Soc Sci Med. 2004 Aug;59(3):473-87.

2. Christensen P. The health-promoting family: a conceptual framework for future research. Soc Sci Med. 2004 Jul;59(2):377-87.

3. Gray NJ, Klein JD, Noyce PR, Sesselberg TS, Cantrill JA. Health information-seeking behaviour in adolescence: the place of the internet. Soc Sci Med. 2005;60(7):1467-78.

4. Chapin JR. Adolescent sex and mass media: a developmental approach. Adolescence 2000 Winter;35(140):799-811.

5. Thorne B. Gender at play: Girl's and boys in schools. New Jersey: Rutgers University Press; 1993.

6. Kaplan EB, Cole L. "I want to read stuff on boys": white, Latina, and black girls reading seventeen magazine and encountering adolescence. Adolescence. 2003 Spring;38(149):141-59.

7. Paquette MC, Raine, K. Sociocultural context of women's body image. Soc Sci Med. 2004 Sep;59(5):1047-58.

8. Short R. Teaching safe sex in school. Int J Gynecol Obstet. 1998;63 (suppl 1):S147-50.

9. Rivkin-Fish M. Sexuality education in Russia: defining pleasure and danger for a fledgling democratic society. Soc Sci Med. 1999 Sep;49(6):80114.

10. Werner-Wilson RJ, Fitzharris JL, Morrissey KM. Adolescent and parent perceptions of media influence on adolescent sexuality. Adolescence. 2004;39(154):303-13.

11. Carpenter LM. Sexual teens, sexual media: investigating media's influence on adolescent sexuality. Book review. J Sex Res. 2003;40(4):403-5.

12. Hacker KA, Amare Y, Strunk N, Horst L. Listening to youth: teen perspectives on pregnancy prevention. J Adolesc Health. 2000 Apr;26(4):27988.

13. Garner A, Sterk HM, Adams S. Narrative analysis of sexual etiquette in teenage magazines. J Commun. 1998;48(4):59-78.

14. Brown JD. Mass media influences on sexuality. J Sex Res. 2002 Feb;39(1):42-5. 
15. Nalewajk, A. Enticement through innovation. Press. 2004;102(7):55-7. (In Polish.)

16. Izdebski Z, Ostrowska A. Sex in Polish.Warsaw: Muza SA; 2003. (In Polish.)

17. Thomas MH. Abstinence-based programs for prevention of adolescent pregnancies. J Adolesc Health. 2000 Jan;26(1):5-17.

18. Wróblewska W. Polish teenage attitudes towards sexuality. Warsaw: School of Economics; 1998. (In Polish.)

19. Manning WD, Longmore MA, Giordano PC. Adolescents' involvement in non-romantic sexual activity. Soc Sci Res. 2005;34(2):384-407.

20. Johnson RL. Pathways to adolescent health: early intervention. J Adolesc Health. 2002 Dec;31(6 Suppl):240-50.

21. Dickson N, Paul C, Herbison P, Silva P. First sexual intercourse: age, coercion, and later regrets reported by a birth cohort. BMJ. 1998 Jan 3;316(7124):29-33

22. Kaestle CE, Halpern CT, Miller WC, Ford CA. Young age at first sexual intercourse and sexually transmitted infections in adolescents and young adults. Amer J Epidemiol. 2005 Apr 15;161(8):774-80.

23. Wątroba M, Paź S. Publications for children and adolescents. Press 2004;102(7):58-60. (In Polish.)

24. Bauer Publishing [homepage on the Internet]. Warsaw: Bauer Publishing Sp. z o.o., Sp.k.; c2002-2006 [cited 2005 Jun 1]. Available from http://www.bauer.pl/tytuly rozw.html?id=24/. (In Polish.)

25. Axel Springer Poland-Dziewczyna [homepage on the Internet]. Warsaw: Axel Springer Poland Sp. z o.o.; c2002-2006 [cited on 2005 Jun 1]. Available from http://axelspringer.pl/mlodziezowe/dziewczyna/. (In Polish.)

26. Bauer Publishing [homepage on the Internet]. Warsaw: Bauer Publishing Sp. Z o.o., Sp.k.; c2002-2006 [cited 2005 Jun 1]. Available from http://www.bauer.pl/tytuly rozw.html?id=22/. (In Polish.)

27. Holzner BM, Oetomo D. Youth, sexuality and sex education messages in Indonesia: issues of desire and control. Reprod Health Matters. 2004 May;12(23):40-9.

28. Whitehead E. Teenage pregnancy: on the road to social death. Int J Nurs Stud. 2001 Aug;38(4):437-46.

29. Stemler S. An overview of content analysis. Prac Assess Res Eval [serial on the internet]. 2001 Jun [cited 2005 Oct 13];7(17):[about 7 p.]. Available from: http://pareonline.net/getvn.asp? $\mathrm{v}=7 \& \mathrm{n}=17$.

30. Kvalseth TO. Note on Cohen Kappa. Psychol Rep. 1989;65(1):223-6.

31. Rudolph KD. Gender differences in emotional responses to interpersonal stress during adolescence. J Adolesc Health. 2002;30(4 Suppl):3-13.

32. Gowen LK, Feldman SS, Diaz R, Yisrael DS. A comparison of the sexual behaviors and attitudes of adolescent girls with older vs. similar-aged boyfriends. J Youth Adolesc. 2004 Apr;33(2):167-75.
33. Raine TR, Jenkins R, Aarons SJ, Woodward K, Fairfax JL, El-Khorazaty MN, et al. Sociodemographic correlates of virginity in seventh-grade black and Latino students. J Adolesc Health. 1999 May;24(5):304-12.

34. Pauluk D. The dynamic development of womens' social roles in Poland in the context of axiologic-normative changes seen in sexual education textbooks after 1989. In: Slany K, Małek A, Szczepaniak-Wiechy I, editors. Value systems and demographic processes. Krakow: NOMOS Publishing House; 2003. p. 205-10. (In Polish.)

35. Stevens-Simon C, Sheeder J. Paradoxical adolescent reproductive decisions. J Pediatr Adolesc Gynecol. 2004 Feb;17(1):29-33.

36. Uskul AK. Women's menarche stories from a multicultural sample. Soc Sci Med, 2004 Aug;59(4):667-79.

37. Kim K, Smith, PK. Childhood stess, behavioural symptoms and motherdaughter pubertal development. J Adolesc. 1998 Jun;21(3):231-40.

38. Kim K, Smith PK, Palermiti AL. Conflict in childhood and reproductive development. Evol Hum Behav. 1997;18(2):109-42.

39. Brückner H, Bearman P. After the promise: the STD consequences of adolescent virginity pledges. J Adolesc Health. 2005 Apr;36(4):271-8.

40. Zimmerman DJ, Santelli JS. School and adolescent health and managed care. Am J Prev Med. 1998 Apr;14(3 suppl):60-6.

41. King H. Contraception for the under 20s. Curr Obstet Gynaecol 2000;10:157-61.

42. Meade CS, Ickovics JR. Systematic review of sexual risk among pregnant and mothering teens in the USA: pregnancy as an opportunity for integrated prevention of STD and repeat pregnancy. Soc Sci Med. 2005 Feb;60(4):661-78.

43. Banner P, Johnson B, editors. Guidelines for Comprehensive Sexuality Education: Kindergarten-12th grade. 3rd ed. [monograph on the Internet]. New York: Sexuality Information and Education Council of the United States; 2004 [cited 2005 June 1]. Available from: http://www.siecus. org/pubs/guidelines/guidelines.pdf.

44. Benson MJ. After the adolescent pregnancy: parents, teens, and families. Child Adolesc Social Work J. 2004;21(5):435-55

45. Somers CL, Paulson SE. Students' perceptions of parent-adolescent closeness and communication about sexuality: relations with sexual knowledge, attitudes, and behaviors. J Adolesc. 2000 Oct;23(5): $629-44$.

46. Blum RW, Nelson-Mmari K. The health of young people in a global context. J Adolesc Health. 2004 Nov;35(5):402-18.

47. Bersamin MM, Walker S, Waiters ED, Fisher DA, Grube JW. Promising to wait: virginity pledges and adolescent sexual behavior. J Adolesc Health. 2005 May;36(5):428-36. 